Pesq. Vet. Bras. 31(6):521-526, junho 2011

\title{
Avaliação da superexpressão da proteína p53 e das mutações no éxon 8 do gene TP53 em carcinomas mamários caninos e glândulas normais ${ }^{1}$
}

\author{
Maria Juliana D. Teixeira ${ }^{2}$, Ana Paula V. Sobral ${ }^{3}$, Maria do Carmo Abreu- \\ e-Lima ${ }^{4}$, Frederico C.L. Maia ${ }^{2}$, Madriano Christilis $^{5}$, Daniela M.B. Souza ${ }^{5}$, \\ Manoel Adrião e Aurea Wischral $2^{*}$
}

\begin{abstract}
Teixeira M.J.D., Sobral A.P.V., Abreu-e-Lima M.C., Maia F.C.L., Christilis M., Souza D.M.B., Adrião M. \& Wischral A. 2011. [Evaluation of immunohistochemical over expression of p53 protein and of mutations in exon 8 of Tp53 gene in canine mammary carcinomas and normal mammary glands.] Avaliação da superexpressão da proteína p53 e das mutações no éxon 8 do gene TP53 em carcinomas mamários caninos e glândulas normais. Pesquisa Veterinária Brasileira 31(6):521-523. Departamento de Medicina Veterinária, Universidade Federal Rural de Pernambuco, Rua Dom Manoel de Medeiros s/n, Recife, PE 52171-900, Brazil. E-mail: aurea@ dmv.ufrpe.br

This study was undertaken with the aim to evaluate the p53 expression, applying the immunohistochemical technique to malignant primary mammary neoplasms histopathologically diagnosed in female dogs, and to investigate exon 8 of the Tp53 suppressor gene for mutation types by means of PCR-RFLP pattern of bands. Nineteen healthy mammary glands were used as a control group (group 1). Samples from 18 cases diagnosed with malignant mammary tumors (group 2), and the contralateral mammary glands (group 3) were collected during the UFRPE Veterinary Hospital routine. The tumors were diagnosed by histopathology and subdivided into grades of malignity. The streptavidin-biotin peroxidase method was used to analyze the immunohistochemical expression of p53, evaluated according to the location and intensity of stain. Expression of p53 protein was not observed in the samples of group 1. On the contrary, it was observed in all malignant tumors; the protein p53 was localized either only in the nucleus or in the nucleus and in the cytoplasm, in samples of group 2. In group 3, expression of p53 protein was observed in the tumors (2 samples) and in normal mammary tissues (4 samples). For the molecular analyses, genomic DNA was extracted and submitted to PCR-RFLP with the following endonuclease enzymes: Alul, BsoBI, Ddel and Smal. The band pattern showed polymorphism between groups, but not between histological variants of tumors. This polymorphism detected mutations in the fragment studied - exon 8 of Tp53 - which could account for changes in nucleotides, located in the restriction sites of the endonuclease enzymes. In conclusion, the immunoexpression of p53 had no relationship with histological subtype or malignity grade, but it can be related to the presence of mammary tumors in female dogs. The PCR-RFLP technique can be an important tool for the study of mammary carcinogenesis in bitches because the polymorphism obtained may allow early diagnosis in tissues of mammary glands.
\end{abstract}

INDEX TERMS: Mammary glands, cancer, p53 expression, RFLP.

\footnotetext{
${ }^{1}$ Recebido em 20 abril de 2010.

Aceito para publicação em 23 de setembro de 2010 .

2 Departamento de Medicina Veterinária, Universidade Federal Rural de Pernambuco (UFRPE), Rua Dom Manoel de Medeiros s/n, Recife, PE 52171-900, Brasil. *Autor para correspondência: aurea@dmv.ufrpe.br

${ }^{3}$ Departamento de Medicina Oral Disciplina de Patologia Bucal, Faculdade de Odontologia, Universidade de Pernambuco (UPE), Av.
} General Newton Cavalcanti 1650, Cx. Postal 1028,Tabatinga,
Camaragibe, PE 54753-901, Brasil.
${ }^{4}$ Centro de Ciências da Saúde, Departamento de Patologia, Univer-
sidade Federal de Pernambuco, Av. Prof. Morais Rego 1235, Cidade
Universitária, Recife, PE 50670-901.
${ }^{5}$ Laboratório de Fisiologia Animal Molecular Aplicada, Departamento
de Morfologia e Fisiologia Animal, UFRPE, Recife, PE. 
RESUMO.- Este estudo foi realizado com o objetivo de avaliar a expressão da proteína p53, pela técnica de imunohistoquímica, em neoplasmas mamários malignos em cadelas, além de investigar mutações no éxon 8 do gene supressor Tp53 por meio do padrão de bandas obtidas por PCR-RFLP. Dezenove mamas de cadelas saudáveis foram usadas como controle (Grupo 1). Amostras de 18 casos de tumores malignos (Grupo 2) e suas glândulas mamárias contralaterais (Grupo 3) foram obtidas na rotina do Hospital Veterinário da UFRPE. Os tumores foram identificados histologicamente e classificados em graus de malignidade. O método da estreptoavidina-biotina peroxidase foi utilizado para a análise da expressão de p53 por imunohistoquímica, de acordo com a localização e intensidade da coloração. A expressão da proteína p53 não foi observada nas amostras do Grupo 1, mas foi encontrada em todas as amostras de tumores malignos (Grupo 2) seja só no núcleo, ou também no citoplasma. No Grupo 3, a expressão foi observada em quatro amostras normais e em duas que apresentavam tumor. Para a análise molecular, o DNA genômico foi extraído e submetido à PCR-RFLP com as seguintes endonucleases: Alul, BsoBI, Ddel e Smal. O padrão de bandas foi polimórfico entre os grupos, mas não entre as variantes tumorais. Esse polimorfismo detectou mutações no fragmento estudado - éxon 8 do gene Tp53- que podem resultar em alterações nos nucleotídeos, localizados nos sítios de restrição das enzimas. Esses achados levam a conclusão de que a imunoexpressão da p53 não tem relação com o subtipo histológico ou grau de malignidade do tumor, mas sim com a presença dos tumores no tecido mamário de cadelas. A PCR-RFLP pode ser usada como importante ferramenta para o estudo da carcinogênese mamária na cadela, possibilitando gerar diagnósticos precoces através do polimorfismo obtido com endonucleases de restrição pré-selecionadas.

TERMOS DE INDEXAÇÃO: Glândula mamária, câncer, expressão de p53, RFLP.

\section{INTRODUÇÃO}

Em medicina veterinária, à semelhança do que ocorre em medicina humana, verifica-se a necessidade de acrescentar aos fatores prognósticos clássicos, tais como: tamanho do tumor, presença de ulceração cutânea e invasão ganglionar linfática, novos parâmetros que auxiliem a decisão terapêutica. Embora experimentos tenham demonstrado a semelhança no comportamento biológico entre tumores de mama em humanos e em caninos, os critérios de graduação dos tumores são pouco utilizados em medicina veterinária (Lagadic \& Estrada 1990).

A prevalência de tumores mamários benignos e malignos em cães varia consideravelmente devido à existência de diferentes métodos de classificação dos tumores e ausência de critérios uniformes para diferenciar os tipos tumorais. Karayannopoulou et al. (2005), após usar o método de graduação proposto por Elston \& Ellis (1991), verificaram a seguinte prevalência para os carcinomas mamá- rios em cadelas: $31,8 \%$ (grau I), 32,9\% (grau II) e 35,3\% (grau III); e observaram que não houve relação entre 0 grau histológico, tamanho do tumor, idade da cadela à mastectomia e metástase para linfonodo.

O rápido diagnóstico na clínica oncológica é essencial, devendo ir além dos diagnósticos clínico e histológico rotineiros, buscando informações sobre todos os aspectos envolvidos através de técnicas e/ou exames mais específicos. O uso da técnica de imuno-histoquímica em Patologia Veterinária tem sido limitado devido à falta de anticorpos para os tecidos animais, no entanto podem ser utilizados os anticorpos que apresentam reatividade cruzada entre antígenos humanos e animais (Keller et al. 2007) e, juntamente com outros exames (citologia e histologia), contribuem para o diagnóstico definitivo e preciso desses tumores (Cassali etal. 2002). Análises imuno-histoquímicas para descoberta de receptores de estrógeno, progesterona, fator de crescimento epidermal, oncogenes, supressores de tumor como o gene $p 53$ (Tp53) entre outros, são de grande valor para fornecer um prognóstico mais acurado para cães com neoplasmas mamários (Hellmén 2005).

Comparado a outros genes envolvidos nas neoplasias mamárias, Tp53 é o gene mais frequentemente mutado nos indivíduos portadores de câncer mamário (Hollstein et al. 1994). Foi detectado, no gene Tp53 canino, que o maior número de mutações está, principalmente, nos éxons 3 a 8 , resultando na perda de controle do ciclo celular e, como consequência, a sobrevivência das células que apresentam alto grau de mutações (Kraegel et al. 1995, Chu et al. 1998, Haga et al. 2001). Estas mutações provocam alterações no potencial invasivo e migratório das células tumorais (Cadwell \& Zambetti 2001).

Embora a avaliação fenotípica de mutantes venha sendo utilizada para detectar mutações, a identificação da maioria das formas de mutações, particularmente as mutações silenciosas, necessita de métodos alternativos mais seguros. As técnicas mais sensíveis e sofisticadas são introduzidas para a detecção das formas mais comuns de mutações em pequena escala, incluindo a reação em cadeia da polimerase (PCR) e o sequenciamento de nucleotídeos (Kraegel et al. 1995). Outros estudos abrangem a técnica PCR-RFLP com o intuito de comparar moléculas de DNA (Qian et al. 2002). A associação de técnicas que avaliam a estrutura molecular do gene $T p 53 \mathrm{com}$ aquelas que evidenciam a expressão gênica contribui para um diagnóstico mais preciso da biologia dos tumores e pode indicar a conduta clínica mais adequada.

O tratamento cirúrgico é o mais comumente recomendado para tumores mamários, porém as mamas aparentemente normais são algumas vezes preservadas. Por isso, a detecção precoce de tumores em mamas anatomicamente íntegras é muito importante para estabelecer tratamentos preventivos. Assim, este estudo foi realizado com o objetivo de avaliar, por imuno-histoquímica, a expressão da proteína p53 em tecido mamário com carcinoma e de glândulas normais do mesmo animal, além de investigar mutações no éxon 8 do gene Tp53, por meio do padrão de bandas obtido pela técnica de PCR-RFLP. 


\section{MATERIAL E MÉTODOS}

Foram utilizadas 19 cadelas submetidas à eutanásia no Centro de Vigilância Ambiental (CVA), em Recife, como fonte de tecido mamário normal (Grupo 1). Na rotina do Hospital Veterinário da Universidade Federal Rural de Pernambuco (UFRPE), foram escolhidas 18 cadelas com carcinoma mamário, submetidas à cirurgia para retirada do tumor, das quais foram retiradas amostras do tecido tumoral (Grupo 2) e das glândulas contralaterais normais (Grupo 3). Este estudo foi aprovado pelo Comitê de Ética em Experimentação Animal da UFRPE (Protocolo 06513/2006).

Foram realizados exames histopatológicos, de rotina, para identificação dos tumores baseado nas características celulares. A classificação utilizada foi a proposta pela Organização Mundial da Saúde (OMS) para caninos e felinos (Misdorp et al. 1999). Para as amostras do Grupo 1, foram avaliadas as características de integridade e normalidade do tecido mamário.

Após a identificação das variantes histológicas encontradas no Grupo 2, os tumores malignos foram classificados de acordo com o grau histológico. Cada amostra recebeu escore entre 1 e 3 para cada parâmetro avaliado (formação tubular, pleomorfismo nuclear e índice mitótico). Os escores foram somados e o grau histológico foi expresso da seguinte forma: baixo ou I (3-5 pontos), intermediário ou II (6-7 pontos), e alto ou III (8-9 pontos) (Karayannopoulou et al. 2005).

Para a análise imuno-histoquímica, foi utilizada a técnica da estreptavidina-biotina peroxidase, otimizada com o sistema de amplificação $\operatorname{LSAB}^{6}$. O anticorpo primário utilizado foi o anti-p53 ${ }^{7}$ (Kumaraguruparan et al. 2006). A reação foi revelada pela utilização do cromógeno diaminobenzidina ${ }^{8}$ e, em seguida, os cortes foram contra-corados com Hematoxilina de Mayer. Para controle positivo da reação foi utilizada uma amostra de carcinoma de células escamosas humano, sabidamente positivo para o anticorpo primário utilizado.

A coloração imuno-histoquímica foi avaliada quanto à localização (nuclear, citoplasmática ou ambas) e à intensidade (baixa + , moderada ++ e intensa +++). O DNA genômico foi extraído de $0,5 \mathrm{~g}$ de tecido mamário pela técnica do fenol:clorofórmio (Maniatis et al. 1989). Os oligonucleotídeos - forward 5': GCTTCTCTCTTCTCACCTG e reverse 5' CTCCTTCACCTCCT CTTGT (Chu et al. 1998) foram utilizados para amplificação do éxon 8 do gene Tp53. As reações de PCR foram realizadas em volume final de 20ill, contendo 50ng do DNA genômico, $20 \mathrm{mM}$ Tris- $\mathrm{HCl}, \mathrm{pH} 8.4 ; 50 \mathrm{mM} \mathrm{KCl} ; 2 \mathrm{mM} \mathrm{MgCl}, 0,2 \mathrm{mM}$ dNTP mix, 10pmoles cada primer e 2,5 U Taq DNA-polymerase ${ }^{9}$. A amplificação foi realizada em termociclador ${ }^{10}$, com os seguintes ciclos: desnaturação inicial à $94^{\circ} \mathrm{C}, 2 \mathrm{~min}$, seguida por 35 ciclos de desnaturação à $94^{\circ} \mathrm{C}, 1 \mathrm{~min}$, anelamento à $58^{\circ} \mathrm{C}, 1 \mathrm{~min}$, e extensão à $72^{\circ} \mathrm{C}, 1 \mathrm{~min}$, com uma extensão final à $72^{\circ} \mathrm{C}$ por $3 \mathrm{~min}$. Os

\footnotetext{
${ }^{6}$ Labeled Streptavidin Biotin para anticorpo primário de camundongo, Dako do Brasil Ltda, Av. do Café 277, São Paulo, SP.

${ }^{7}$ Clone 1A4/1:50/60 min, Dako do Brasil Ltda, Av. do Café 277, São Paulo, SP.

8 3,3'diaminobenzidine, DAB, Sigma-Aldrich Brasil Ltda, Av Nações Unidas 23043, Alto de Pinheiros, São Paulo, SP.

${ }^{9}$ Invitrogen Brasil Ltda, Rua Breno Ferraz do Amaral 408, São Paulo, SP.

10 Eppendorf Personal Mastercycler®, Eppendorf do Brasil Ltda, Rua Ferreira de Araújo, 221, conj.15, São Paulo, SP.

${ }^{11}$ PureLink PCR Purification Kit®, Invitrogen Brasil Ltda, Rua Breno Ferraz do Amaral 408, São Paulo, SP.

12 New England Biolabs,240 County Road, Ipswich, MA, USA.
}

produtos resultantes foram avaliados em gel de agarose a $2 \%$ corado com brometo de etídio.

Os produtos de PCR foram purificados ${ }^{11}$ e submetidos a sequenciamento automático (MegaBACE 1000) com kit DYEnamic ET Dye Terminator (Thermo Sequenase ${ }^{\mathrm{TM}}$ II DNA Polimerase). A análise das sequencias de nucleotídeos foi feita com base na sequencia conhecida publicada no GeneBank (S77819).

As enzimas de restrição (Alul, Aval, BsoBl, Ddel, Rsal e Smal) ${ }^{12}$ foram selecionadas a partir das sequências do éxon 8. As reações de RFLP foram realizadas de acordo com as indicações do fabricante. O DNA fragmentado foi submetido à eletroforese em gel de agarose (2\%), corado com brometo de etídio.

$\mathrm{Na}$ análise estatística foi utilizado o teste Kruskal-Wallis para testar a hipótese de homogeneidade das distribuições da contagem das células coradas, segundo o grau de malignidade. O teste exato de Fisher foi utilizado para testar a hipótese de não associação entre o grau de malignidade e a intensidade da marcação. Em todos os testes foi adotado o nível de significância de $\mathrm{P} \leq 0,05$.

\section{RESULTADOS}

No Quadro 1 são mostradas as variantes histológicas dos tumores e seus respectivos graus histológicos.

Não foi observada qualquer expressão para a proteína p53 mutante nas amostras do Grupo 1, demonstrando que não há marcação imuno-histoquímica quando a proteína não mutante está presente, significando atividade normal da p53. Por outro lado, marcação positiva foi observada nos tumores malignos. Essas marcações foram localizadas no citoplasma (Fig.1) ou no núcleo (Fig.2), isoladamente ou em associação. A intensidade da marcação variou de baixa a moderada independente da variante histológica (Quadro 2).

O grau histológico e a intensidade da imunoexpressão não apresentaram associação estatisticamente significativa $(P>0,05)$. $O$ índice médio das células marcadas e o grau histológico revelaram inexistência de heterogeneidade entre as distribuições das contagens das células marcadas segundo o grau de malignidade.

Nas glândulas mamárias contralaterais ao tumor, duas amostras (11.2\%) apresentaram células neoplásicas e a lesão foi caracterizada como carcinoma (Quadro 3). Nessas duas amostras com células neoplásicas e em quatros amostras histologicamente normais, foi observada a expressão de p53. A intensidade da marcação variou de baixa a intensa (Quadro 2).

\section{Quadro 1. Classificação, número $(\mathrm{N})$ e frequência (\%) relacionados às variantes histológicas de tumores mamários malignos e aos graus histológicos em cadelas}

\begin{tabular}{lccc}
\hline \multirow{2}{*}{ Variante histológica } & & \multicolumn{2}{c}{ Tumores malignos } \\
\cline { 3 - 4 } & $\mathrm{N}$ & $\%$ & Grau histológico \\
\hline Carcinoma sólido & 4 & 22.2 & II \\
Carcinoma in situ & 4 & 22.2 & I \\
Carcinoma tubular & 4 & 22.2 & $2 /$ III; $2 /$ II \\
Carcinoma papilar & 2 & 11.1 & II \\
Carcinoma sem especificação & 1 & 5.6 & II \\
Carcinoma em tumor misto & 1 & 5.6 & II \\
Carcinossarcoma & 2 & 11.1 & III \\
Total & 18 & 100.0 & -
\end{tabular}




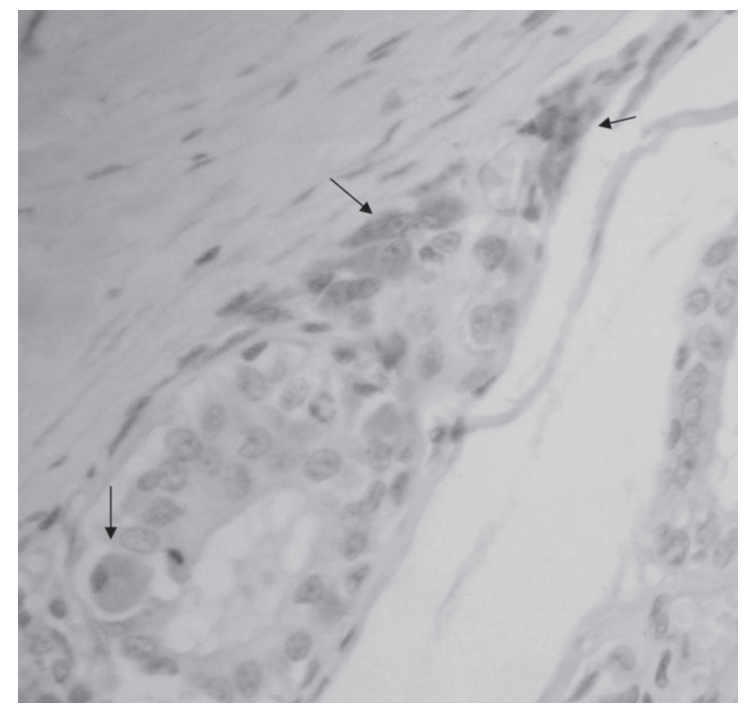

Fig.1. Imunoexpressão citoplasmática da proteína p53 em células ductais neoplásicas (setas) de tumor maligno mamário em cadela (IHQ, p53). 200x.

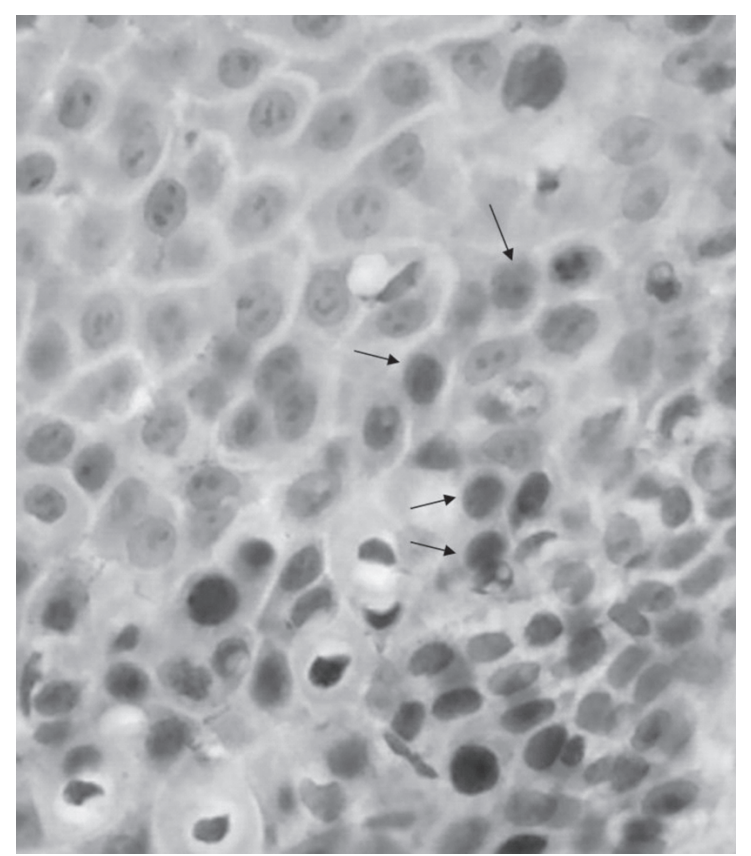

Fig.2. Imunoexpressão nuclear da proteína p53 em células neoplásicas (setas) de tumor maligno mamário em cadela (IHQ, p53). 200x.

Das seis enzimas selecionadas, somente quatro (Alul, BsoBI, Ddel e Smal) geraram polimorfismo no número de pares de bases e nas clivagens, diferenciando glândulas normais daquelas com tumor (Quadro 4). O padrão de bandas de cada enzima mostrou polimorfismo entre os grupos, mas não dentro dos grupos (animal normal e com tumor). Portanto foi impossível relacionar o padrão de polimorfismo com o grau histológico do tumor.

Os cortes com a enzima Smal apresentaram alteração na localização e número dos sítios de restrição, resultando em fragmentos de diferentes tamanhos quando a glân-
Quadro 2. Expressão da proteína p53 em cada variante histológica de tumor em glândula mamária de cadelas (Grupo 2)

\begin{tabular}{ccccccc}
\hline Caso & Tipo histológico & MN & MC & MNC TCM & $\begin{array}{c}\text { Inten- } \\
\text { sidade }\end{array}$ \\
\hline 1 & & & & & & + \\
2 & Carcinoma & 2 & 3 & - & 5 & + \\
3 & Carcinoma in situ & - & - & 5 & 5 & ++ \\
4 & Carcinoma in situ & 2 & 5 & - & 7 & ++ \\
5 & Carcinoma in situ & 6 & 2 & - & 8 & ++ \\
6 & Carcinoma papilar & 10 & 4 & - & 6 & ++ \\
7 & Carcinoma papilar & - & - & - & 10 & + \\
8 & Carcinoma sólido & 3 & - & - & 6 & ++ \\
9 & Carcinoma sólido & 3 & - & - & 3 & + \\
10 & Carcinoma sólido & 1 & 4 & - & 5 & + \\
11 & Carcinoma sólido & 2 & 2 & - & 4 & + \\
12 & Carcinoma tubular & - & 2 & - & 2 & + \\
13 & Carcinoma tubular & 5 & 1 & - & 6 & ++ \\
14 & Carcinoma tubular & 5 & 4 & - & 9 & + \\
15 & Carcinoma tubular & 3 & - & - & 3 & + \\
16 & Carcinoma em tumor misto & 5 & 4 & - & 9 & ++ \\
17 & Carcinossarcoma & 8 & 5 & & 13 & ++ \\
18 & Carcinossarcoma & 2 & & - & 2 & ++ \\
\hline
\end{tabular}

$\mathrm{TCM}=$ total de células marcadas, $\mathrm{MN}=$ marcação nuclear, $\mathrm{MC}=$ marcação citoplasmática,

MNC = marcação citoplasmática e nuclear, + baixa, ++ moderada, +++ intensa, - sem marcação.

Quadro 3. Imunoexpressão da proteína p53 em glândula mamária de cadela, contralateral à mama com tumor

\begin{tabular}{ccccccc}
\hline $\begin{array}{c}\text { Mama } \\
\text { contralateral }\end{array}$ & $\mathrm{N}$ & $\mathrm{MN}$ & $\mathrm{MC}$ & $\mathrm{MNC}$ & $\mathrm{TCM}$ & Intensidade \\
\hline Carcinoma & 1 & - & - & 10 & 10 & +++ \\
Carcinoma & 1 & - & 1 & - & 1 & ++ \\
Normal & 1 & 4 & 2 & & 6 & ++ \\
Normal & 1 & - & 1 & - & 1 & + \\
Normal & 1 & 3 & 5 & 1 & 9 & ++ \\
Normal & 1 & 1 & - & - & 1 & + \\
Normal & 12 & - & - & - & - & -
\end{tabular}

$\mathrm{N}=$ № de casos, $\mathrm{TCM}$ = total de células marcadas, $\mathrm{MN}=$ marcação nuclear, $\mathrm{MC}=$ marcação citoplasmática, $\mathrm{MNC}=$ marcação citoplasmática e nuclear, + baixa, ++ moderada, +++ intensa, - sem marcação.

Quadro 4. Padrões de polimorfismo de bandas (pares de bases - pb) após PCR-RFLP com enzimas endonucleases em amostras de glândula mamária de cadelas com e sem tumores

\begin{tabular}{cccc}
\hline & \multicolumn{3}{c}{ Amostras } \\
\cline { 2 - 4 } Enzima & Mama & Tumor & Tecido mamário \\
endonuclease & normal & mamário & contralateral \\
\hline Alul & $200 \mathrm{pb}$ & $50-150-200 \mathrm{pb}$ & $50-150-200 \mathrm{pb}$ \\
BsoBl & $25-50-75 \mathrm{pb}$ & $50-75 \mathrm{pb}$ & $50-75 \mathrm{pb}$ \\
Ddel & $50-75-100 \mathrm{pb}$ & $25-75-100 \mathrm{pb}$ & $50-75-100 \mathrm{pb}$ \\
Smal & $80-120 \mathrm{pb}$ & $50-75 \mathrm{pb}$ & $50-75 \mathrm{pb}$
\end{tabular}

dula normal foi comparada com aquela portadora de tumor do mesmo animal.

A análise dos fragmentos resultantes da ação da enzima BsoBI revelou dois tipos de alelos no éxon 8 do Tp53 em cadelas normais, correspondendo a duas (75 - 75 $50 \mathrm{pb}$ ) ou três (75 - 75 - 25 - 25pb) clivagens. Entretanto, glândulas mamárias com tumor bem como as contralaterais 
do mesmo animal, só apresentaram duas clivagens. Por outro lado, a enzima Alul não cortou as sequências das cadelas normais, que se mantiveram com 200pb. Entretanto, as amostras de glândula mamária com tumor e das contralaterais apresentaram heterozigose caracterizada por bandas de 200, 150 e 50pb.

A heterozigose também foi observada com a enzima Ddel, nas cadelas normais e nas mamas contralaterais aos tumores, caracterizada por uma (100-100bp) e duas (75-75-50bp) clivagens. Nas mamas tumorais, a heterozigose foi caracterizada pelo aumento no número de sítios de restrição de um dos alelos, gerando fragmentos menores (75-75-25-25bp).

\section{DISCUSSÃO}

Os resultados deste trabalho revelaram expressão para p53 independente do caráter benigno ou maligno dos tumores, com variação da intensidade da marcação, independente de seus subtipos histológicos.

A expressão da p53 em glândulas salivares com tumor maligno também não apresentou diferença significante em vários subtipos histológicos de tumor (Souza et al. 2005). Níveis de expressão heterogênea de p53 em tumores mamários de caninos foram encontrados pela técnica RT-qPCR (Klopfleisch \& Gruber 2009), usando glândulas normais como controle. Isto indica que este marcador tem uma fraca relação com o tipo tumoral.

Schafer et al. (1998) não encontraram diferenças na marcação imuno-histoquímica de p53, porém a expressão nuclear da proteína ocorreu apenas em carcinomas sólidos. Em nosso estudo, todos os casos de carcinoma sólido (quatro amostras) apresentaram marcação nuclear, porém, em dois destes, a expressão também aconteceu no citoplasma e um deles teve marcação mais intensa no citoplasma do que no núcleo.

A expressão citoplasmática aumentada da p53 é consequência do sequestro da proteína alterada neste compartimento celular, o que proporciona sua inativação relacionada ao processo neoplásico, independente da ação do estrógeno e da resistência ao tratamento com tamoxifen, em linhagens celulares de câncer de mama (Lilling et al. 2002).

Behrens et al. (2001) também observaram marcação no citoplasma de células tumorais benignas em mamas. A expressão da proteína nestes tumores ocorreu principalmente no citoplasma, bem como nos tumores ductais (tubular), lobular, e carcinomas in situ; assim, este tipo de expressão da proteína p53, pode estar relacionado a diferenças na regulação do ciclo celular, que implicam no aumento do risco potencial de invasão do tumor.

A expressão de p53 mutante, nas glândulas normais de animais portadores de tumor, indica a possibilidade de estas glândulas desenvolverem tumor no futuro.

Acredita-se que a marcação citoplasmática é mais frequente do que a literatura informa. Este fato indica uma nova via de sinalização para estes tumores, que pode ser ou não uma forma de transformação como característica de um tumor mais agressivo. Porém outros estudos são necessários para elucidar estes achados.

Estudos utilizando a técnica PCR-RFLP para analisar mutações do gene Tp53 em humanos têm se limitado ao códon 72 (Osborne et al. 1991, Xu et al. 2005), com o objetivo de associá-las ao câncer ou detectar pacientes com maior sensibilidade à quimioterapia. Em cães, o estudo do códon 72 não é possível, uma vez que esta região, rica em prolina, foi perdida durante o processo de evolução da espécie (Kraegel et al. 1995, Veldhoen \& Milner 1998). Entretanto, a utilização do éxon 8 neste trabalho, foi motivada pela alta frequência de mutações encontradas neste éxon, o qual é considerado um dos pontos mais afetados por mutações no gene Tp53. Este ponto é o domínio central da proteína p53, que se liga ao DNA para exercer sua função reguladora, onde se encontram os códons 273 e 282, que correspondem ao aminoácido arginina (Levine 1997, Chu et al. 1998, Muto et al. 2000, Lee \& Kweon 2002). A observação de diferentes padrões, representando o polimorfismo gerado pelas enzimas utilizadas, reflete a existência de mutações que afetam os códons relacionados com os sítios de restrição das enzimas, ou em outros códons, gerando novos sítios de restrição.

Os códons 278 e 301 (Smal e Bsobl) e 297 (Ddel) codificam o aminoácido prolina (Pro), um importante indicador de atividade na proteína p53. Estudos sobre o códon 72 de humano demonstraram que a homozigose Pro/Pro torna a proteína menos eficiente do que a homozigose para o aminoácido arginina (Arg/Arg) (Osborne et al. 1991, Yi \& Lee 2006). Os códons citados são próximos aos códons que têm importância para a função da proteína (Hainaut \& Hollstein 2000), os quais podem estar afetados por inserções ou deleções de nucleotídeos, que alteram a sequência das bases, e se encontram em quantidades significantes nos tecidos alterados.

Embora as alterações na heterozigose não tenham sido estudadas em caninos como em tumores de humanos, o resultado das análises das enzimas utilizadas neste trabalho (Alul, BsoBl e Ddel) comprova que, em cadelas, também é possível relacionar esta característica com mutações no éxon 8 do gene Tp53. Estudos posteriores poderão determinar um códon e uma endonuclease de restrição que possam ser utilizados no diagnóstico precoce da doença, a exemplo do códon 72 em humanos.

As mutações observadas no éxon 8 foram as mais frequentes e estiveram relacionadas com diferentes tipos de tumores, inclusive nas mamas que ainda não apresentavam alterações histopatológicas. Isto já havia sido observado em sequências do gene $p 53$ em cadelas com tumor de mama, em estudo prévio, ainda não publicado.

O fato de não ter havido diferença entre os tecidos de mamas com tumor e as normais do mesmo animal, com a reação das enzimas Alul, BsoBl e Smal, reforça a idéia de que os tecidos que ainda não apresentaram alterações visíveis, já se encontravam alterados no nível molecular e, portanto, potencialmente capazes de desenvolver tumores ao longo do tempo, uma vez que as alterações nos 
genes supressores de tumor podem ocorrer anos antes de se iniciar a transformação neoplásica (Lee \& Kweon 2002). Adiciona-se ainda, a expressão imuno-histoquímica da proteína mutante que foi observada em quatro amostras de mamas contralaterais ao tumor que se mostravam histologicamente normais.

Portanto, o reconhecimento precoce da alteração genética irá permitir a intervenção ou tratamento a tempo de evitar a progressão do tumor e formação de metástases que afetam significantemente a sobrevida das pacientes.

Conclui-se que, entre as amostras estudadas, a imunoexpressão da proteína p53 não pode ser relacionada com o subtipo ou grau histológico dos tumores, mas sim com a presença dos tumores no tecido mamário de cadelas. Embora o estudo pela técnica de PCR-RFLP apresente resultados dependentes de mutações em locais específicos, que geralmente ocorrem de forma aleatória, esta técnica pode vir a ser uma importante ferramenta para o estudo da carcinogênese mamária na cadela, possibilitando gerar diagnósticos precoces através do polimorfismo obtido com endonucleases de restrição pré-selecionadas.

Agradecimentos.- À Coordenação de Aperfeiçoamento de Pessoal de Nível Superior (CAPES), pela concessão de bolsa de doutorado e à Fundação de Amparo à Ciência e Tecnologia do Estado de Pernambuco (FACEPE).

\section{REFERÊNCIAS}

Behrens P., Brinkmann U., Fogt F., Wernert N. \& Wellmann A. 2001. Implication of the proliferation and apoptosis associated CSE1L/CAS gene for breast cancer development. Anticancer Res. 21:24132417.

Cadwell C. \& Zambetti G.P. 2001. The effects of wild-type p53 tumor suppressor activity and mutant p53 gain-of-function on cell growth. Gene 277:15-30.

Cassali G.D., Gartner F. \& Schmitt F.C. 2002. Pleomorphic lobular carcinoma of the canine mammary gland: Histopathologic and immunohistochemical features. Arq. Bras. Med. Vet. Zootec. 54:592594.

Chu L.L., Rutteman G.R., Kong J.M.C., Ghahremani M., Schmeing M., Misdorp W., Van Garderen E. \& Pelletier J. 1998. Genomic organization of the canine p53 gene and its mutation status in canine mammary neoplasia. Breast Cancer Res. Treat. 50:11-25.

Elston C.W. \& Ellis I.O. 1991. Pathological prognostic factors in breast cancer: Experience from a large study with long-term follow-up. Histopathology 19:403-410.

Haga S., Nakayama M., Tatsumi K., Maeda M., Imai S., Umesako S., Yamamoto H., Hilgers J. \& Sarkar N.H. 2001. Overexpression of the p53 gene product canine mammary tumors. Oncol. Rep. 8:12151219.

Hainaut P. \& Hollstein M. 2000. p53 and human cancer: The first thousand mutations. Adv. Cancer Res. 77:81-137.

Hellmén E. 2005. Complex mammary tumours in the female dog: A review. J. Dairy Sci. 72:90-97.

Hollstein M., Rice K., Greenblatt M.S., Soussi T., Fuchs R., Sorlie T., Hovig E., Smith-Sorensen B., Montesano R. \& Harris C.C. 1994. Database of p53 gene somatic mutations in human tumors and cell lines. Nucleic Acids Res. 22:3551-3555.

Karayannopoulou M., Kaldrymidou E., Constantinidis T.C. \& Dessiris A. 2005. Histological grading and prognosis in dogs with mammary carcinomas: Application of a human grading method. J. Comp. Pathol. 133:246-252.

Keller S.M., Schade B., Rickenbacher A.B., Brugnera E., Wergin M.C., Muller E.J., Suter M.M. \& Guscetti F. 2007. A comprehensive test system to identify suitable antibodies against p53 for immunohistochemical analysis of canine tissues. J. Comp. Pathol. 137:5970 .

Klopfleisch R. \& Gruber A.D. 2009. Differential expression of cell cycle regulators p21, p27 and p53 in metastasizing canine mammary adenocarcinomas versus normal mammary glands. Res. Vet. Sci. 87:9196.

Kraegel S.A., Pazzi K.A. \& Madewell B.R. 1995. Sequence analysis of canine p53 in the region of exons 3-8. Cancer Lett. 92:181-186.

Kumaraguruparan R., Prathiba D. \& Nagini S. 2006. Of humans and canines: Immunohistochemical analysis of PCNA, Bcl-2, p53, cytokeratin and mammary tumours. Res. Vet. Sci. 81:218-224.

Lagadic M. \& Estrada M. 1990. Tumeurs mammaires de la chienne: critères du pronostic histologique et intérêt d'um grading. Rec. Med. Vet. Ec. Alfort 166:1035-1042.

Lee C. \& Kweon O.K. 2002. Mutation of canine tumor supresor gene p53 in a mammary gland adenocarcinoma and a malignant mast cell tumor. Vet. Clin. 19:195-198.

Levine A.J. 1997. p53 the cellular gatekeeper for growth and division. Cell 88:323-331.

Lilling G., Nordenberg J., Rotter V., Goldfinger N., Peller S. \& Sidi Y. 2002. Altered subcellular localization of p53 in estrogen-dependent and estrogen-independent breast cancer cells. Cancer Invest. 20:509-517.

Maniatis T., Fritsch E.F. \& Sambrook J. 1989. Molecular Cloning: A laboratory manual. $2^{\text {nd }}$ ed. Cold Spring Harbor Laboratory Press, New York. 1659p.

Misdorp W., Else R.W. \& Hellmen E. 1999. Histological classification of mammary tumors of the dog and cat. Armed Forces Institute of Pathology, Washington, DC. 59p.

Muto T., Wakui S., Takahashi H., Maekawa S., Masaoka T., Ushigome S. \& Furusato M. 2000. p53 gene mutations occurring in spontaneous benign and malignant mammary tumors of the dog. Vet. Pathol. 37:248253.

Osborne R.J., Merlo G.R., Mitsudomi T., Venesio T., Liscia D.S., Cappa A.P.M., Chiba I., Takahashi T., Nau M.M., Callahan R. \& Minna J.D. 1991. Mutations in the p53 gene in primary human breast cancers. Cancer Res. 51:6194-6198.

Qian G-S., Luang S-Y., He X., Groopman J.D. \& Jackson P.E. 2002. Sensitivity of electrospray ionization mass spectrometry detection of codon 249 mutations in the p53 gene compared with RFLP. Cancer Epidemiol. Biomarkers Prev. 11:1126-1129.

Schafer K.A., Kelly G., Schrader R., Griffith W.C., Muggenburg B.A., Tierney L.A., Lechner J.F., Janovitz E.B. \& Hahn F.F. 1998. A canine model of familial mammary gland neoplasia. Vet. Pathol. 35:168-177.

Souza K.C.N., Faria P.R.F., Cardoso S.V., Dib L.L., Candelori I. \& Loyola A.M. 2005. Immunohistochemical expression of p53 on the biological behavior of salivary gland tumors. J. Bras. Patol. Med. Lab. 41:189-195.

Veldhoen N. \& Milner J. 1998. Isolation of canine p53 cDNA and detailed chracterization of full length canine p53 protein. Oncogene 16:10771084.

Xu Y., Yao L., Ouyang T., Li J., Wang T., Fan Z., Lin B., Lu Y. \& Xie Y. 2005. p53 Codon 72 polymorphism predicts the pathologic response to neoadjuvant chemotherapy in patients with breast cancer. Clin. Cancer Res. 11:7328-7333.

Yi S.Y. \& Lee W.J. 2006. A p53 genetic polymorphism of gastric cancer: Difference between early gastric cancer and advanced gastric cancer. World J. Gastroenterol. 12:6536-6539. 